\title{
LETRAMENTOS E A EDUCAÇÃO CTS (CIÊNCIA, TECNOLOGIA E SOCIEDADE): REFLEXÕES SOBRE A FORMAÇÃO DE CIDADÃOS CRÍTICOS NA CULTURA DIGITAL
}

\author{
LETTERS AND SCIENCE, TECHNOLOGY AND SOCIETY \\ (STS) EDUCATION: REFLECTIONS ON THE \\ FORMATION OF CRITICAL CITIZENS IN THE DIGITAL \\ CULTURE
}

\author{
Ana Paula Matos Bazilioa \\ Camila do Nascimento Cultrib \\ Veronica de Sousa Gomesc \\ Daniel Ribeiro Silva Milld
}

\begin{abstract}
RESUMO
Introdução: O presente artigo parte do seguinte princípio: como o letramento digital pode ser compatível com os pressupostos da educação CTS (Ciência, Tecnologia e Sociedade)? A fim de responder os possíveis questionamentos o texto trata algumas temáticas como: sociedade ágrafa, sociedade grafocêntrica digital e tradicional, alfabetização, letramento, letramento digital, letramento digital crítico, letramento informacional, educação e CTS. Objetivo: compreender quais os recursos que os letramentos e a educação CTS podem fornecer para auxiliar a formação de cidadãos conscientes. Metodologia: foi realizado uma breve revisão de literatura sobre o tema nas bases de dados: BRAPCI, SCIELO, BDTD, Google Scholar e o ambiente virtual AVAdmin/UFSCar. Resultado: no contexto das tecnologias da informação e comunicação, encontramos na literatura estudada os recursos sobre letramento digital e a educação CTS para formação de cidadãos conscientes. Conclusão: conclui-se, que a educação CTS contempla os pressupostos do letramento digital, a alfabetização científica e tecnológica, com vistas à participação cidadã consciente, ou seja, quanto mais os sujeitos forem letrados digitalmente maior a possibilidade de participação ativa na sociedade da informação.
\end{abstract}

a Doutoranda do Programa de Pós-Graduação em Ciência, Tecnologia e Sociedade da Universidade Federal de São Carlos (UFSCar). E-mail: anapaulambazilio@gmail.com.

b Doutoranda do Programa de Pós-Graduação em Ciência, Tecnologia e Sociedade da Universidade Federal de São Carlos (UFSCar). E-mail: milacultri@gmail.com.

c Doutoranda do Programa de Pós-Graduação em Ciência, Tecnologia e Sociedade da Universidade Federal de São Carlos (UFSCar). E-mail: veronisg22@gmail.com.

d Doutor em Educação pela Universidade Federal de Minas Gerais (UFMG). Docente do Departamento da Universidade Federal de São Carlos (UFSCar). E-mail: mill@ead.ufscar.br. 
Descritores: Educação. Tecnologias da informação e comunicação. Letramentos. Cultura digital.

\section{INTRODUÇÃO}

O presente trabalho, centra-se, em analisar as possíveis relações entre o letramento digital e o enfoque CTS (Ciência, Tecnologia e Sociedade), no contexto educacional brasileiro. Algumas questões motivaram a elaboração desse artigo: O letramento digital pode potencializar o letramento tradicional? Como o letramento digital crítico pode contribuir para a cidadania? Como a noção de letramento pode ser associada aos objetivos da educação e do campo CTS? No intuito de compreender essas questões, tratamos de forma breve algumas temáticas tangentes, tais como: sociedades ágrafas, grafocêntricas tradicionais e digitais, alfabetização, letramento tradicional, letramento digital, letramento digital crítico, letramento informacional, educação e campo CTS.

Metodologicamente, o artigo é um ensaio teórico, decorrente da análise de textos levantados por meio de revisão de literatura. Para enriquecer os nossos questionamentos e argumentos, realizamos um breve levantamento bibliográfico nas seguintes bases de dados: BRAPCI, BDTD, SCIELO, Google Scholar e o ambiente virtual AVAdmin/UFSCar. Os termos pesquisados foram letramento e letramento digital, sendo relacionados com a Educação e o campo CTS.

Em nossa breve revisão e análise da literatura a respeito da temática letramento e suas tipologias, destacamos autores envolvidos com a temática há décadas: SOARES (1998, 2002, 2004); BUZATO (2006, 2009) e XAVIER (2007). Identificamos também contribuições de autores em textos mais recentes, tais como: VITORINO, PIANTOLA (2009); MILL, JORGE (2012); BORGES (2016); CARVALHO, SOUZA (2012); PINHEIRO, ARAÚJO (2018); CRUZ, SOUZA (2018); SORJ (2018).

Para contextualizar as noções de letramento, educação e CTS, consultamos reflexões dos seguintes autores: SANTOS (1999); ROCHA (2000); BAZZO, VON LINSINGEN e PEREIRA (2003); AULER e BAZZO (2001); PALACIOS (2001); MAMEDE e ZIMMERMANN (2005); PINHEIRO, SILVEIRA e 
BAZZO (2007); GRINSPUN (2009); HOFFMANN (2011); STRIEDER (2012); REIS, DUARTE (2017); AZEVEDO, OGÉCIME (2020).

$\mathrm{Na}$ atualidade, vivemos na denominada sociedade da informação e do conhecimento, onde a informação consiste em um elemento chave, em plena articulação com as Tecnologias da Informação e Comunicação (TICs). São tempos com transformações sociais aceleradas e intensas, sendo importante e necessário refletirmos sobre o letramento, especialmente quando partimos do princípio de que o letramento digital crítico pode contribuir para formação de cidadãos questionadores e reflexivos. Essa reflexão está associada com os objetivos da Educação CTS, que tem por objetivo auxiliar a formação de cidadãos críticos, sujeitos responsáveis pelo desenvolvimento científico da sociedade emergente. Desta forma, a Educação CTS é pautada na alfabetização científica e tecnológica, bem como na participação cidadã de forma crítica e consciente. Este é o mote da reflexão deste texto.

\section{DISCUSSÃO SOBRE LETRAMENTOS NO BRASIL: BASES PARA PENSAR A EDUCAÇÃO CTS}

Temos vivido transformações aceleradas na sociedade atual, especialmente em decorrência do desenvolvimento tecnológico. Todavia, a educação não tem acompanhado todas essas mudanças da sociedade. A discussão sobre letramento se instala nesse descompasso entre educação e sociedade em geral.

Nessa perspectiva, vale considerar a classificação de tipos de sociedade, feita por Mill e Jorge (2013; 2018), em função do uso que fazem das Tecnologias de Informação e Comunicação (TIC). Segundo os autores, há as sociedades ágrafas, as sociedades grafocêntricas tradicionais e, mais recentemente, as sociedades grafocêntricas digitais. As sociedades ágrafas são marcadas pela cultura oral, pela identidade e pela memória, tendo a oralidade como forma de comunicação entre os sujeitos. Ou seja, nessas sociedades ágrafas não há registro escrito, não sendo importante a noção de letramento por não haver o código escrito. Portanto, o momento de transição das sociedades ágrafas para sociedades 
grafocêntricas tradicionais é marcado pela invenção e uso intensivo da escrita. Assim, sujeitos que não dominam o código escrito são excluídos de socialmente de determinadas práticas sociais. Mais recentemente, emergem as denominadas sociedades grafocêntricas digitais, que são permeadas pela cultura digital e marcadas pelo uso intensivo das tecnologias digitais de informação e comunicação (TDIC). Desta forma, surge mais uma parcela de excluídos, aqueles que não dominam o código digital. Pessoas não letradas digitalmente são desfavorecidas em práticas típicas da sociedade grafocêntrica digital, sendo privadas dos benefícios das TDIC (MILL; JORGE, 2013; 2018). Percebe-se, portanto, a importância do letramento, como meio de participação social e pertencimento.

Há quase duas décadas, Soares (2002) apontou uma imprecisão na definição do termo letramento, em textos publicados sobre educação no Brasil. Ela afirmou que não há uma variedade em sua conceituação, mas há sim diversas caracterizações do processo de letramento - o que reforça a importância desta breve revisão de literatura sobre a temática.

Para Soares (2004), o conceito de letramento emerge no Brasil nos anos de 1980 - embora em outros países a discussão seja mais antiga, e desde o início teve grande repercussão nas áreas de educação e de linguagem. Inicialmente, as noções de alfabetização e letramento se confundiam na discussão brasileira, mas posteriormente ficou estabelecida a distinção entre os dois termos. A alfabetização pode ser compreendida como um processo de "aquisição e apropriação do sistema de escrita alfabético e ortográfico" (SOARES, 2004, p. 16). Conforme Mamede e Zimmermann (2005, p. 1), a alfabetização compreende as "habilidades e conhecimentos que constituem a leitura e a escrita, no plano individual". Importante ressaltar que o processo de alfabetização deve acontecer num contexto de letramento, sendo o letramento entendido, numa concepção mais ampla, como o "conjunto de práticas sociais ligadas à leitura e escrita em que os indivíduos se envolvem em seu contexto social" (SOARES, 2004, p. 17).

Para Carvalho e Souza (2012, p. 196), há níveis de letramento, que se diferem pela "apropriação das competências de ler e escrever e seu uso contínuo e satisfatório nas práticas sociais". Esses autores apontam que, antes, os 
Letramentos e a educação CTS (Ciência, Tecnologia e Sociedade): reflexões sobre a formação de cidadãos críticos na cultura digital

alfabetizados eram representados pelos indivíduos "capazes de codificar e decodificar o próprio nome ou redigir um pequeno bilhete" (CARVALHO; SOUZA, 2012, p. 196). Porém, com as novas exigências da sociedade da informação, tornou-se necessário a adoção de novas classificações:

Alfabetizados: aqueles que conhecem a tecnologia do ler e do escrever; e Letrados: aqueles que detém as competências de desenvolvimento da leitura e da escrita (nos suportes impresso, digital etc.) e desenvolvem habilidades de crítica e autorreflexão ao fazerem o uso efetivo da tecnologia da escrita nas práticas sociais.

Apesar das diferenças entre os termos alfabetização e letramento, ambos precisam ser considerados como processos "interdependentes e indissociáveis". Importante reconhecer que o desenvolvimento da alfabetização se dá por meio das atividades de letramento (CARVALHO; SOUZA, 2012, p. 197).

Alguns autores mencionam o conceito de letramento no plural (letramentos), pela quantidade e diversidade que envolvem o processo de leitura e escrita. Conforme ressalta Buzato (2006):

Letramento, ou mais precisamente letramentos, são práticas sociais e culturais que têm sentidos específicos dentro de um grupo social, que ajudam a manter a coesão e a identidade do grupo, e são apreendidos em eventos coletivos do uso da leitura e escrita, e por isso são diferentes em diferentes contextos sociais (BUZATO, 2006, p. 4).

Essas noções de letramento (ou letramentos, no plural) são típicas da sociedade grafocêntrica mais tradicional, embora sejam incorporadas pela cibercultura. Com a emergência das TDIC e, por decorrência, da cultura digital, passa a ser comumente adotada a expressão letramento digital, entre outras terminologias.

Na figura 1, apresentaremos as várias denominações de contemporâneas para letramentos.

Figura 1 - Designações de letramentos 


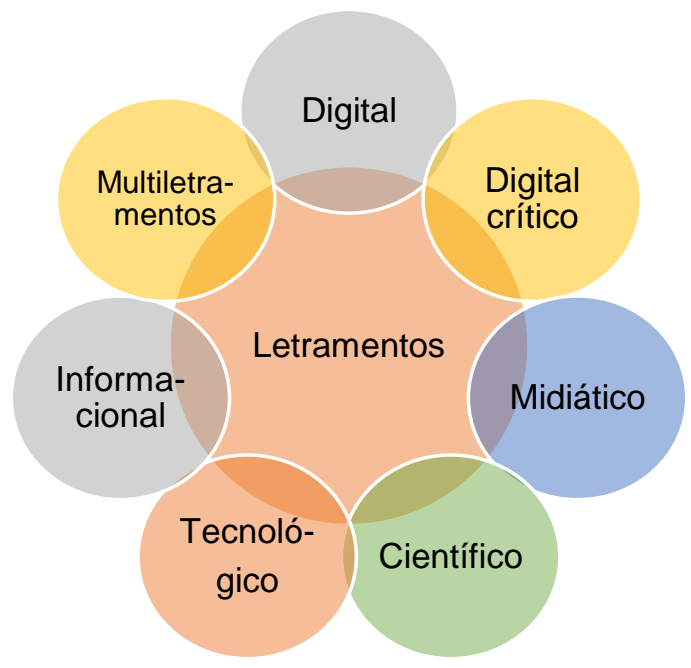

Fonte: elaborado pelos autores (2020)

Esta diversidade ou pulverização nas denominações ocorre porque "as práticas de letramentos tradicionais começam se tornar insuficientes para que 0 sujeito esteja efetivamente inserido na sociedade" (BORGES, 2016, p. 717). Ou seja, foi preciso expandir a noção de letramento para conceber a efetividade da participação em práticas sociais típicas das sociedades grafocêntricas digitais (MILL; JORGE, 2018).

\section{LETRAMENTO DIGITAL CRÍTICO: NOÇÕES GERAIS}

Como mencionado, a sociedade contemporânea é permeada pela cultura digital e, assim, emerge o conceito de letramento digital, tendo como significado amplo a habilidade de leitura e escrita em ambientes digitais. Xavier (2007) conceitua letramento digital como:

A necessidade dos indivíduos dominarem um conjunto de informações e habilidades mentais que devem ser trabalhadas com urgência pelas instituições de ensino, a fim de capacitar o mais rápido possível os alunos a viverem como verdadeiros cidadãos neste novo milênio cada vez mais cercado por máquinas eletrônicas e digitais (XAVIER, 2007, p. 133).

Acreditamos que a discussão sobre o letramento digital é essencial em países como o Brasil, marcados pelo subdesenvolvimento e pela exclusão social. Afinal, sem devido domínio do código digital, será maior o grau de exclusão de 
práticas de cidadania e participação social. Isto é, o processo de exclusão social e digital tende a ser mais acirrado nesses países, limitando a participação daqueles sujeitos que ainda não dominam o código escrito e/ou o uso das tecnologias digitais de informação e comunicação. Esse processo de exclusão é perverso, pois ser letrado também significa questionar e participar, de alguma forma, do contexto político e científico do nosso país; significa conhecer e ter voz em decisões sociopolíticas. Portanto, o letramento digital mostra-se essencial como meio para a emancipação e cidadania.

Nesse sentido, é relevante abordar também o letramento midiático. Este tipo de letramento está relacionado "às habilidades e competências que envolvem o acesso, a apropriação, a capacidade de compreensão e análise, o consumo, a produção, a avaliação e a criação de conteúdo em uma variedade de contextos de mídias e linguagens" (CRUZ; SOUZA, 2018, p. 388). As autoras mencionam que o letramento midiático deve ser pensado por dois vieses:

"a) no âmbito do desenvolvimento de competências e habilidades dos sujeitos para inserção e acesso às tecnologias digitais e a informação; e b) é importante refletirmos sobre o papel que as mídias exercem na formação do cidadão" (CRUZ; SOUZA, 2018, p. 388).

O letramento digital crítico perpassa a ideia de formação de cidadãos críticos, autônomos capazes de expressar, produzir e interagir com as tecnologias digitais de informação e comunicação, abarcando de certa forma também as mídias. Como afirmou Sorj (2018), o novo espaço [internet] de comunicação e convivência virtual exige um esforço educacional para formar ecidadãos conscientes das potencialidades, mas também os desafios e perigos que surgem com a esfera pública virtual.

Em consonância com as noções de letramentos, vale abordar também o conceito de competência informacional: "uma arte neoliberal, que vai desde saber como usar os computadores e acessar a informação até a reflexão crítica sobre a natureza da informação em si, sua infraestrutura técnica e o seu contexto e impacto social, cultural e mesmo filosófico" (VITORINO; PIANTOLA, 2009, p. 141).

Conforme Carvalho e Souza (2012, p. 199-200), a competência 
informacional está relacionada ao "[...] desenvolvimento de habilidades de pensar e ler criticamente, ensinando a aprender a aprender [...]", não pode ser tida como um processo, mas sim entendida como um estado ao qual se chega por meio "[...] da eficiência e da efetividade no uso da informação, na fruição da literatura e na busca e geração continuada de novas informações que impulsionam a sociedade informacional" (CARVALHO; SOUZA, 2012, p. 199200). Outro conceito que é importante mencionarmos é o de letramento informacional: "[...] é fundamental para que os indivíduos reconheçam as informações necessárias, aperfeiçoem suas habilidades enquanto leitores críticos por meio de novos conhecimentos críticos e gerados [...]" (REIS, DUARTE, 2017, p. 18).

Vale registrar que o conceito de letramento que norteou a nossa reflexão é o letramento digital crítico. Essa noção não pressupõe apenas o uso da leitura e da escrita em suas múltiplas linguagens em ambientes digitais, mas também 0 questionamento da produção e da circulação desse material na rede de computadores. Esse processo exige níveis mais elaborados de manipulação de determinadas tecnologias, além da leitura e da escrita (PINHEIRO; ARAUJO, 2018, p. 386).

Em outras palavras, a noção de letramento digital crítico envolve muito mais do que saber usar as tecnologias digitais, alcança também a busca pela informação com criticidade dos materiais na rede. Ela abarca o saber localizar, filtrar, avaliar e questionar a informação em rede. Nesse sentido, temos um sujeito mais ativo, participativo, crítico e emancipado, superando a ideia de um simples sujeito apático, simples receptor de informações.

Observa-se que, no contexto da cultura digital, estabelece-se um novo desafio: os sujeitos, além de estarem aptos a utilizar as práticas de leitura e escrita, precisam estar letrados digitalmente. Por esse motivo, é comum a associação da noção de letramento aos conceitos de inclusão, exclusão social e digital. Como já mencionamos, os sujeitos que não dominam essas práticas de leitura, escrita e tecnologias digitais enfrentarão dificuldades de inserção na sociedade contemporânea, ou mais precisamente na sociedade da informação 
e do conhecimento, terão participação limitada no contexto da cultura digital.

Portanto, o letramento representa uma forma de abrir possibilidades de acesso do cidadão a espaços de participação política e emancipatória. Assim, quanto maior for o domínio do conhecimento, melhores serão as condições de participação ativa na sociedade. Portanto, a reflexão sobre letramento na cultura digital guarda íntima relação com o campo CTS no contexto educativo.

\section{RELAÇÕES ENTRE LETRAMENTO, EDUCAÇÃO E O CAMPO CTS}

Para relacionar letramento e educação CTS, faz-se necessário, contextualizar o surgimento do campo de estudos: Ciência, Tecnologia e Sociedade (CTS). Assim como a Ciência da Informação, o campo CTS é uma área interdisciplinar, recente, que surgiu na década de 1960, se consolidando na década de 70, e abrangendo diversas disciplinas (Sociologia, Filosofia, Educação, entre outras). O campo de estudos CTS surge como uma crítica a visão positivista da ciência, as pessoas acreditavam veemente na ciência como um progresso de bemestar social. Esse excesso de credibilidade na ciência e tecnologia pode representar um perigo. "Mal sabem as pessoas que atrás de grandes promessas de avanços tecnológicos escondem-se lucros das classes dominantes. Essas que, muitas vezes persuadindo as classes menos favorecidas, impõe seus interesses" (PINHEIRO; SILVEIRA; BAZZO, 2007, p. 72).

Segundo Bazzo, Von Linsingen e Pereira (2003) a dimensão social da ciência e da tecnologia está relacionada com a sociedade no âmbito educacional, seja na formação básica ou superior. Dessa forma, o campo de estudos CTS tem como objetivo potencializar a formação de cidadãos questionadores, sendo esses responsáveis pelo desenvolvimento científico da sociedade em geral.

Com propósito de apontar caminhos, os estudos CTS seguem com uma visão social da ciência. Segundo Bazzo, Von Linsingen e Pereira (2003, p. 119), o campo CTS investiga "tanto os fatores sociais que influem na mudança científicotecnológica como no que diz respeito às consequências sociais e ambientais". Dessa forma, há um foco sobre uma sociedade de riscos e de modernização reflexiva. Sendo uma de suas temáticas "a que relaciona a comunicação e a 
informação à participação nos processos decisórios que envolvem 0 desenvolvimento de C\&T", visto que a qualidade da informação e a forma de representação de Ciência e Tecnologia disponíveis acabam por influenciar na compreensão da sociedade quanto aos riscos e seus benefícios (HOFFMANN, 2011, p. 51). Esta questão da participação relaciona-se com a noção de letramento já apresentada, no sentido de fomentar a capacidade do cidadão participar efetivamente de práticas sociais e políticas, de modo emancipado, crítico e consciente, nesta sociedade grafocêntrica digital (MILL; JORGE, 2013; 2018).

No Brasil, o país ainda é fortemente marcado por problemas sociais, principalmente no que tange à educação, como: analfabetismo, analfabetismo funcional, educação precária, acesso desordenado às tecnologias digitais, dificuldade de incorporação dos benefícios das TDIC no seio educacional, entre outros. Nesse sentido, mostra-se necessária a implementação da educação com enfoque CTS no contexto brasileiro, porque "a cultura de participação da sociedade em questões nacionais ainda é bastante débil" (AULER; BAZZO, 2001, p. 3).

Conforme Palacios et al. (2003), os estudos CTS se desenvolvem em três direções: pesquisa acadêmica, políticas públicas e educação. Essas três linhas são inter-relacionadas, complementam-se e tem por objetivo geral auxiliar na formação de cidadãos críticos e emancipados, sendo capazes de intervir na realidade atual. Ou como sugeriu Sorj (2018), esta discussão instala-se em um contexto que pressupõe uma "educação cívica para a democracia na sociedade da informação [que] deve fortalecer os valores associados à cultura oral - ouvir e sentir, de fato, o outro - e à cultura escrita - argumentar, refletir" (SORJ, 2018, p. 150). Daí a importância do letramento digital, para participação efetiva de práticas sociopolíticas típicas da cultura digital, da sociedade grafocêntrica digital.

De acordo com Hoffmann (2011), existem vários modelos para diminuir o déficit de transmissão ou transferência do conhecimento científico à população. O de participação pública é o mais próximo da função de mediador da comunicação. Esse modelo busca levar o indivíduo a desempenhar o papel de democrático e ser um cidadão participativo nas políticas que envolvem os 
assuntos em Ciência e Tecnologia (C\&T) que valoriza o diálogo entre os que praticam e não praticam ciência. Assim, cada vez mais os cientistas têm se preocupado "em estimular não só a participação, mas também o engajamento do público na tomada de decisões no processo científico" (HOFFMANN, 2011, p. 55). Nesse sentido, qual a importância de refletirmos sobre a temática de letramento na educação CTS?

Concordamos que o objetivo da educação CTS:

É o desenvolvimento de uma cidadania responsável - uma cidadania individual e social para lidar com problemas que têm dimensões científicas e tecnológicas, num contexto que se estende para além do laboratório e das fronteiras das disciplinas. Tornar a Ciência revestida de mais significado para o aluno, de forma a prepará-lo melhor para lidar com as realidades da vida atual e para poder planificar o seu próprio futuro, é uma das suas aspirações básicas (SANTOS, 1999, p. 25).

Para esse autor, a alfabetização científica e tecnológica inclui uma diversidade de propostas da educação CTS (SANTOS, 1999), especialmente com o surgimento das tecnologias de informação e comunicação, que promoveram mudanças significativas com relação à interação, produção e disseminação do conhecimento. Também vale ressaltar que essa nova configuração também influenciou na formulação do currículo e nas metodologias de ensino- aprendizagem, incluindo os estudos CTS no contexto educativo (HOFFMANN, 2011, p. 39).

Como já mencionamos anteriormente, esta discussão está no mote do nosso texto: uma reflexão sobre o papel da Educação CTS articulada com a noção de letramento, no contexto da cultura digital, como meio para melhor formação do sujeito participativo, ativo, crítico e emancipado. A seguir, exploraremos um pouco mais esta noção.

A construção de uma cidadania crítica, com a participação ativa por parte dos cidadãos na sociedade, requer conhecimentos no âmbito CTS. Nesse sentido, como já indicamos, o letramento digital crítico pode auxiliar na potencialização da cidadania, da participação ativa no contexto da sociedade grafocêntrica digital, na obtenção das plenas condições de participar, avaliar e tomar decisões a respeito do desenvolvimento científico e tecnológico. 
Para entender melhor a relação entre a educação CTS e o letramento digital, vale buscar um argumento de Grinspun (2009). A autora afirma que a relação entre educação e tecnologias

Pressupõe uma dimensão pedagógica nos fundamentos de sua atividade técnica e científica, possibilitando oferecer os conhecimentos que vise à formação do homem inserido na cultura de seu tempo, na sociedade em que participa e nas mudanças que acredita coletivamente poder alcançar (GRINSPUN, 2009, p. 32).

O meio que o cidadão contemporâneo experimenta uma cultura diferente daquela anterior à emergência das TDIC. Agora o cidadão deve ter condições e participar da sociedade grafocêntrica digital, permeada por possibilidades e limitações diversas e que exige, necessariamente, letramento digital como meio para a participação crítica.

Rocha (2000) afirma que no conceito de cidadania estar imbricando a noção de igualdade, no que tange aos direitos e deveres do cidadão. Mas, ao mesmo tempo, este conceito de cidadania associado a igualdade nos remete a "estratificação social" acirrando assim a desigualdade em um país capitalista como o Brasil.

A conscientização é um processo que permite ao homem compreender a realidade que o cerca, como ela se estrutura, o que ele é e a reagir a essa realidade, assumindo seu destino e dos seus semelhantes com autonomia, buscando sempre melhores condições de vida (ROCHA, 2000, p. 43).

Já a cidadania digital abrange a participação política na cultura digital, representa as habilidades dos sujeitos para participar da sociedade da era da informação. Dessa maneira, a cidadania digital é tida como a capacidade para fazer parte de uma sociedade em rede - por meio do uso das tecnologias ampliou-se as possibilidades de se exercer cidadania. (REGO, 2012). Assim, de acordo com Castells (1999), podemos pensar que:

[...] se a representação política e os responsáveis pela tomada de decisão tiverem condições de estabelecer uma relação com essas novas fontes de contribuição de cidadãos interessados na política, sem que o processo fique restrito a uma elite tecnologicamente capacitada, um novo modelo de sociedade 
civil pode ser construído, possibilitando a popularização da democracia, via eletrônica (CASTELLS, 1999, p. 411).

Para Hoffmann (2011, p. 42), a educação CTS abarca "a interação entre professores, alunos e materiais didáticos, a formação crítica do cidadão revela a importância do desenvolvimento da autonomia no processo de ensino e aprendizagem". O que torna a participação colaborativa de todos os envolvidos essencial no processo de inclusão social e na participação da população quanto às tomadas de decisão e contribuição na formulação de políticas públicas de ciência, tecnologia e inovação (HOFFMANN, 2011, p. 46).

Pinheiro, Silveira e Bazzo (2007, p. 74) apontam para o "enfoque CTS no contexto educativo". Ressaltando, assim, a importância da difusão da temática sobre ciência, tecnologia e sociedade em sala de aula e na educação formal em geral, considerando que o enfoque CTS pode abranger a educação básica e superior. Nessa perspectiva, Auler e Bazzo (2001, p. 3) também mencionam a importância de despertar o interesse dos alunos para a ciência, com abordagem tecnológica voltada para o cotidiano. A educação CTS objetiva formar cidadãos letrados científica e tecnologicamente. Quando Strieder (2012, p. 13) analisa as diferentes abordagens do enfoque CTS, destaca a "alfabetização científica e tecnológica", o "letramento científico e tecnológico" e a "educação para sustentabilidade".

Esses aspectos apresentados acima indicam que o letramento digital é um dos pressupostos da educação CTS no contexto atual, da cultura digital. Observa-se, portanto, que a educação CTS e o letramento digital se aproximam, no sentido em que objetivam o despertar de sujeitos que desenvolvam habilidades e competências críticas e reflexivas sobre a informação de natureza científica e tecnológica para inclusão desse indivíduo na sociedade contemporânea.

Assim, podemos compreender que o letramento digital está voltado para a educação científica e os objetivos que a norteiam, na medida em que o letramento refere-se "às práticas efetivas de leitura e escrita no plano social" (MAMEDE; ZIMMERMANN, 2005, p. 1) e, também à capacidade de amplo uso das tecnologias em sua vida social. No âmbito da ciência encontramos o letramento científico, que 
se preocupa em "preparar o indivíduo para a vida em uma sociedade científica e tecnológica, na qual o conhecimento assume um papel essencial, dentro de uma perspectiva crítica da ciência e da tecnologia" (MAMEDE; ZIMMERMANN, 2005, p. 2), e assim saber utilizar o conhecimento científico e tecnológico no seu dia a dia. A relação do letramento científico com o campo CTS vai além do uso do conhecimento científico, abrange também as possibilidades de interação dos cidadãos com elementos da Ciência e Tecnologia na vida social. A ciência é compreendida como uma prática social, capaz de discutir sobre os aspectos de sua produção, divulgação e aplicação, e possibilita o "controle sobre a ciência e a tecnologia que a sociedade detém" (MAMEDE; ZIMMERMANN, 2005, p. 2).

\section{RESULTADOS}

De acordo com os autores suscitados abaixo, vimos as possíveis relações entre letramento e a educação CTS, visando a formação de cidadãos conscientes.

Figura 2 - Recursos sobre letramento digital e a educação CTS para formação de cidadãos conscientes.

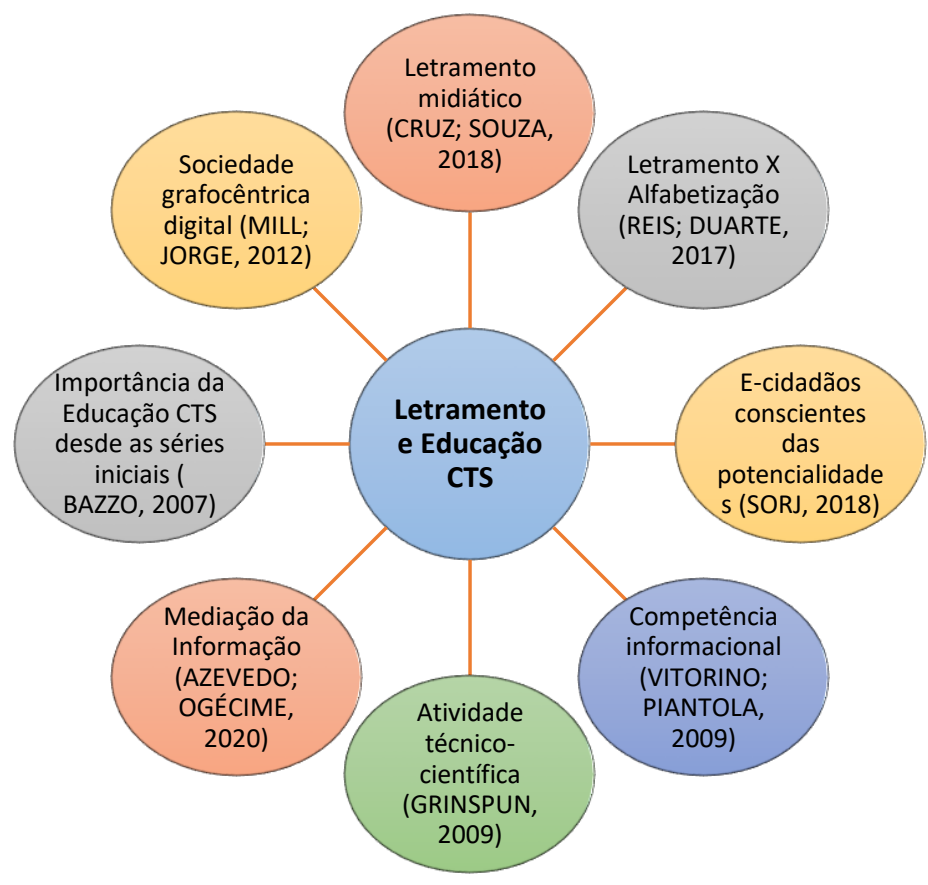

Fonte: elaborado pelos autores (2020) 
Por fim, o que podemos depreender sobre a relação entre letramento, educação e o campo CTS, está relacionado às práticas que intencionam formar o indivíduo para atuar nesta sociedade como um sujeito social crítico, com condições de intervir, participar e transformar a realidade a sua volta. Contudo, as articulações se fazem necessárias desde a formação básica dos indivíduos. Nesse sentido, importante que essas três searas (letramento, educação e o campo CTS) estejam sempre articuladas, tratadas mesmo de modo interdependente e complementares.

\section{CONSIDERAÇÕES FINAIS}

Com o avanço da ciência e do desenvolvimento tecnológico, aumenta-se também a produção de novos conhecimentos, o que contribui para novas oportunidades de bem-estar e melhoria para a sociedade de uma maneira geral. Contudo, existem os riscos, que delimitam novas exigências. Entende-se que, com o avanço da ciência e das tecnologias, especialmente nos últimos anos, o objetivo de formar cidadãos letrados foi se intensificando (e se modificando), buscando suprir as demandas da sociedade.

Contudo, percebe-se que a existência da desigualdade social sempre deixou um déficit no meio desse progresso, especialmente no contexto capitalista, em que a busca primordial está voltada para os lucros dos investimentos feitos em prol do desenvolvimento. Visto que, o desenvolvimento implica em contínuo processo de mudanças e de investimentos, a classe dominante deseja e busca progressivamente ganhos e poder, tornando outros excluídos de benefícios das ciências, das tecnologias, da educação e do conhecimento.

A cultura digital nos remete a novas formas dos sujeitos se relacionarem entre si e com o mundo, propiciando novas formas de leitura e escrita e suscitando novos processos cognitivos e novas relações com a informação e o conhecimento. Faz-se necessário que os sujeitos se encontrem inseridos na sociedade da informação, sendo cidadãos críticos e reflexivos, capazes de buscar, usar, filtrar, interagir e questionar sobre as informações recebidas, sem 
perder de vista sua capacidade e oportunidade de produção de informações. Nesse cenário, surgem novas tipologias de letramentos: digital, midiático, crítico, tecnológico, científico, informacional entre outros. Sabemos da importância de compreender esses diversos tipos, mas não foi esse o escopo deste artigo. Não houve a pretensão de esgotar esta frente de reflexão. Importa aqui ressaltar necessária a potencialização da cidadania através da educação. A educação em CTS, associada aos letramentos, é um viés da ciência que vem sendo utilizada para alcançar tais objetivos.

Findamos a nossa reflexão no desejo de termos cumprido a inspiração de demonstrar a importância das relações entre o campo CTS, a Educação o os letramentos - especialmente no sentido de tornar pessoas capazes de exercer com eficiência o seu papel de cidadão ativo, emancipado e crítico. Por fim, registramos a necessidade de reflexões mais aprofundadas sobre esses temas e, principalmente, novos estudos que apontem os seus desempenhos.

\section{REFERÊNCIAS}

AULER, D.; BAZZO, W. A. Reflexões para implementação do movimento CTS no contexto educacional brasileiro. Ciência \& Educação, Bauru, v. 7, n. 1, p. 113, 2001. Disponível em:

http://www.scielo.br/scielo.php?script=sci_arttext\&pid=S1516-

73132001000100001. Acesso em: 28 jul. 2019.

AZEVEDO, K. R. de; OGÉCIME, M. O papel do bibliotecário como mediador da informação na busca pelo letramento informacional. RDBCI: Revista Digital de Biblioteconomia e Ciência da Informação, Campinas, SP, v. 18, p.1-17, 2020. Disponível em: https://periodicos.sbu.unicamp.br/ojs/index.php/rdbci/article/view/8654473/2189 6 Acesso em: 20 jan. 2020.

BAZZO, W. A.; VON LINSINGEN, I.; PEREIRA, L. T. do V. (Ed.). Introdução aos estudos CTS (Ciência, Tecnologia e Sociedade). Madri: OEI, 2003. p. 119- 155.

BORGES, F. G. B. Um olhar rizomático sobre o conceito de letramento digital. Trab. linguíst. apl., Campinas, v. 55, n. 3, p. 703-730, set./dez. 2016. Disponível em: http://www.scielo.br/scielo.php?pid=S010318132016000300703\&script=sci_abstract\&tlng=pt. Acesso em: 17 jun. 2019. 
BUZATO, M. El K. Letramento e inclusão: do estado-nação à era das TIC. D.E.L.T.A., São Paulo, v. 25, n. 1, p. 1-38, 2009.

BUZATO, M. El K. Letramento digital: um lugar para pensar em internet, educação e oportunidades. In: CONGRESSO IBERO-AMERICANO EDUCAREDE, 3., São Paulo, 2006. Anais [...] São Paulo: CENPEC, 2006.

CARVALHO, M. da C.; SOUZA, N. C. R. Letramento literário e mediação da leitura na escola: algumas considerações. In: MOURA, Maria Aparecida (Org.). Educação científica e cidadania: abordagens teóricas e metodológicas para a formação de pesquisadores juvenis. Belo Horizonte: UFMG/PROEX, 2012. p. 195-204.

CASTELLS, M. A era da informação: economia, sociedade e cultura. v. 2. O poder da identidade. Tradução de Klauss Brandini Gerhardt. São Paulo: Paz e Terra, 1999.

CRUZ, D. M.; SOUZA, T. F. Letramento midiático (verbete). In: MILL, D. (Org.). Dicionário crítico de educação e tecnologias e de educação a distância. Campinas: Papirus, 2018. p. 387- 390.

GRINSPUN, M. P. S. Z. (Org.). Educação tecnológica: desafios e perspectiva. 3. ed. rev. ampl. São Paulo: Cortez, 2009. 293 p.

HOFFMANN, W. A. M. (Org.). Ciência, tecnologia e sociedade: desafios da construção do conhecimento. São Carlos, SP: EdUFSCar, 2011. 312 p.

MAMEDE, M.; ZIMMERMANN, E. Letramento científico e CTS na formação de professores para o ensino de ciências. Enseñanza de las Ciencias: Revista de Investigación y Experiencias Didácticas, Barcelona, número extra, 2005. VII Congreso Int.

MILL, D.; JORGE, G. Sociedade grafocêntrica digital. In: MILL, D. (org.). Dicionário crítico de educação e tecnologias e de educação a distância. Campinas: Papirus, 2018. p. 192-194.

MILL, D.; JORGE, G. Sociedades grafocêntricas digitais e educação: sobre letramento, cognição e processos de inclusão na contemporaneidade. In: MILL, D. (Org.). Escritos sobre educação: desafios e possibilidades para ensinar e aprender com tecnologias emergentes. São Paulo: Paulus, 2012.

PALACIOS, E. M. G. (Ed.). Introdução aos estudos CTS: ciência, tecnologia e sociedade. Espanha: OEI, 2003. 172 p. (Cadernos de Ibero-América, n. 1).

PALACIOS, E. M. G. et al. (Org.). Ciencia, Tecnología y Sociedad: una aproximación conceptual. Madrid: Organización de Estados Iberoamericanos para la Educación, la Ciencia y la Cultura, 2001. 
PINHEIRO, N. A. M.; SILVEIRA, R. M. C. F.; BAZZO, W. A. Ciência, tecnologia e sociedade: a relevância do enfoque CTS para o contexto do ensino médio. Ciência \& Educação, v. 13, n. 1, p. 71-84, 2007. Disponível em: http://www.scielo.br/scielo.php?pid=S151673132007000100005\&script=sci_abstract\&tIng=pt. Acesso em: 20 jun. 2019.

PINHEIRO, R.; ARAÚJO, J. Letramento tecnológico (verbete). In: MILL, D. (Org.). Dicionário crítico de educação e tecnologias e de educação a distância. Campinas: Papirus, 2018. p. 390-394.

REGO, B. P. C. Cidadania digital e redes sociais: a ampliação do horizonte cívico a novos mecanismos de participação política" referente ao tema cidadania e redes sociais. 2012. Disponível em:

http://cfcul.fc.ul.pt/projectos/cidadania/coloquio/Comunicacoes/BrunoRego.pdf. Acesso em: 03 set. 2019.

ROCHA, M. P. C. A questão cidadania na sociedade da informação. Ci. Inf., Brasília, v. 29, n. 1, p. 40-45, jan./abr. 2000. Disponível em:

http://www.scielo.br/pdf/ci/v29n1/v29n1a4.pdf. Acesso em: 19 ago. 2019.

REIS, G. A.; DUARTE, A. B. S. Leitura e letramento informacional na universidade: um hiato, um construto fragmentado ou um dilema? Informação \& Informação, Londrina, v. 22, n. 3, p. 136-157, dez. 2017. Disponível em: http://www.uel.br/revistas/uel/index.php/informacao/article/view/26075. Acesso em: 18 jan. 2020.

SANTOS, M. E. V. M. Desafios pedagógicos para o século XXI: suas raízes em fontes de mudança de natureza científica, tecnológica e social. Lisboa: Livros Horizonte, 1999.

SOARES, M. Letramento e alfabetização: as muitas facetas. Revista Brasileira de Educação, n. 25, p. 5-17, jan./fev./mar./abr. 2004. Disponível em: http://www.scielo.br/pdf/rbedu/n25/n25a01.pdf. Acesso em: 17 jun. 2019.

SOARES, M. Novas práticas de leitura e escrita: letramento na cibercultura. Educ. Soc., Campinas, v. 23, n. 81, dez. 2002. SOARES, M. O que é letramento e alfabetização. In: SOARES, M. Letramento: um tema em três gêneros. Belo Horizonte: Autêntica, 1998.

SORJ, B. Democracia e sociedade da informação (verbete). In: MILL, D. (Org.). Dicionário crítico de educação e tecnologias e de educação a distância. Campinas: Papirus, 2018. p. 149-151.

STRIEDER, R. B. Abordagens CTS na educação científica no Brasil: sentidos e perspectivas. $282 \mathrm{f}$. Tese (Doutorado em Ciências) - Faculdade de Educação, Instituto de Física, Química e Biociências, Universidade de São Paulo, São Paulo, 2012. Disponível em: https://www.teses.usp.br. Acesso em: 17 jun. 2019. 
Letramentos e a educação CTS (Ciência, Tecnologia e Sociedade): reflexões sobre a formação de cidadãos críticos na cultura digital

VITORINO, E. V.; PIANTOLA, D. Competência informacional - bases históricas e conceituais: construindo significados. Ci. Inf., Brasília, DF, v. 38, n. 3, p. $130-$ 141, set./dez. 2009. Disponível em:

http://www.scielo.br/pdf/ci/v38n3/v38n3a09.pdf. Acesso em: 17 jun. 2019.

XAVIER, A. C. As tecnologias e a aprendizagem (re)construcionista no Século XXI. Revista Hipertextus, v. 1, p. 1-9, 2007. Disponível em:

http://www.hipertextus.net/volume1/artigoxavier.pdf. Acesso em: 16 jun. 2019.

\title{
LETTERS AND SCIENCE, TECHNOLOGY AND SOCIETY (STS) EDUCATION: REFLECTIONS ON THE FORMATION OF CRITICAL CITIZENS IN THE DIGITAL CULTURE
}

\begin{abstract}
Introduction: This article starts from the following principle: how can digital literacy be compatible with the assumptions of CTS (Science, Technology and Society) education? In order to answer possible questions, the text addresses some topics such as: graphic society, digital and traditional graphocentric society, literacy, literacy, digital literacy, critical digital literacy, information literacy, education and CTS. Objective: to understand what resources literacies and CTS education can provide to assist the formation of conscientious citizens. Methodology: a brief literature review on the topic was carried out in the databases: BRAPCI, SCIELO, BDTD, Google Scholar and the virtual environment AVAdmin / UFSCar. Result: in the context of information and communication technologies, we find in the studied literature the resources on digital literacy and CTS education for the formation of conscious citizens. Conclusion: it is concluded that CTS education contemplates the assumptions of digital literacy, scientific and technological literacy, with a view to conscious citizen participation, that is, the more the subjects are digitally literate, the greater the possibility of active participation in the information society.
\end{abstract}

Descriptors: Education. Technology of the information and communication. Lettering. Digital culture.

\section{LETRAMIENTO Y EDUCACIÓN CTS (CIENCIA, TECNOLOGÍA Y SOCIEDAD): REFLEXIONES SOBRE LA FORMACIÓN DE CIUDADANOS CRÍTICOS EN LA CULTURA DIGITAL}

\begin{abstract}
RESUMEN
Introducción: este artículo parte del siguiente principio: ¿cómo puede la alfabetización digital ser compatible con los supuestos de la educación CTS (Ciencia, Tecnología y Sociedad)? Para responder posibles preguntas, el texto aborda algunos temas como:
\end{abstract}


Letramentos e a educação CTS (Ciência, Tecnologia e Sociedade): reflexões sobre a formação de cidadãos críticos na cultura digital

sociedad gráfica, sociedad grafocéntrica digital y tradicional, alfabetización, alfabetización, alfabetización digital, alfabetización digital crítica, alfabetización informacional, educación y CTS. Objetivo: comprender qué recursos pueden proporcionar las alfabetizaciones y la educación CTS para ayudar a la formación de ciudadanos conscientes. Metodología: se realizó una breve revisión de la literatura sobre el tema en las bases de datos: BRAPCI, SCIELO, BDTD, Google Scholar y el entorno virtual AVAdmin / UFSCar. Resultado: en el contexto de las tecnologías de la información y la comunicación, encontramos en la literatura estudiada los recursos sobre alfabetización digital y educación CTS para la formación de ciudadanos conscientes. Conclusión: se concluye que la educación CTS contempla los supuestos de alfabetización digital, alfabetización científica y tecnológica, con miras a una participación ciudadana consciente, es decir, cuanto más alfabetizados digitalmente los sujetos, mayor es la posibilidad de participación activa en la sociedad de la información.

Descriptores: Educación. Tecnologías de la información y la comunicación. Letramiento. Cultura digital.

Recebido em: 08.03.2020

Aceito em: 04.02.2021 